Pain Physician. 2003;6:295-300, ISSN 1533-3159

\title{
Radiation Exposure to the Spinal Interventionalist Performing Lumbar Discography
}

\author{
Kenneth P. Botwin, MD*, Glenn S. Fuoco, DO*, Francisco M. Torres, MD*, Robert D. Gruber, DO*, \\ Constantine C. Bouchlas, MD*, Ramon Castellanos, MD*, and Sanjiv Rao, BA**
}

To evaluate radiation exposure to the spinal interventionalist performing lumbar discography.

A prospective study on four spinal interventionalists who performed 106 consecutive lumbar discograms (levels) on 37 patients with low back pain.

Radiation exposure was monitored with the assistance of a radiological technologist (RT) who allocated four (4) dosimetry badges to all spinal interventionalists performing Discograms on consecutive pa- tients being referred for evaluation of possible discogenic pain. The badges were placed on the ring finger, glasses and both the inside and outside of the lead apron worn by the interventionalist.

The mean fluoroscopy time per procedure was 57.24 seconds. The mean/ cumulative exposure per procedure was $3.66(+0.915) / 390(+9.750) \mathrm{mREM}$ at the "ring" badge, $2.35(+0.635) / 251(+6.275)$ mREM at the "outside apron" badge, $1.49(+0.373) / 159(+3.975) \quad m R E M$ at the "glasses" badge. A statistically significant higher radiation exposure was found on discograms at the $L_{5} / S_{1}$ level compared to the $\mathrm{L} 4 / 5$ and $\mathrm{L} 3 / 4$ levels.

Our study illustrates that radiation exposure to the spinal interventionalist performing lumbar discography is well within safety limits.

Keywords: Discography, fluoroscopy, radiation safety
Chronic low back pain has become a major problem for millions of patients. Many of these patients have non-neurogenic back pain that may be of discogenic origin. The intervertebral disc has been thought to be a source of lower back pain (1-3). Lumbar discography has evolved into a necessary diagnostic test to identify patients who exhibit symptomatic internal disc disruption (IDD)(4-6). The methodology and efficacy in evaluating the patient with presumed symptomatic IDD is reviewed elsewhere (7-10).

With the advent of intradiscal electrothermal annuloplasty (IDEA) (11-14) for the treatment of symptomatic IDD the discogram has become a more utilized and important diagnostic aide in the treatment of patients with lumbar pain.

Lumbar discography is performed utilizing fluoroscopic guidance. Through the aide of fluoroscopy the intervertebral disc can be reached with spinal needles in such a way as to minimize potential complications. The technique was initially de-

From: *Florida Spine Institute, Clearwater, FL, and **University of South Florida, Department of Mathematics, Clearwater, FL. Address Correspondence: Kenneth P. Botwin, MD, Florida Spine Institute, 2250 Drew Street, Clearwater, FL 33765 . E-mail: contactus @floridaspineinstitute.com

Funding: There was no external funding in preparation of this manuscript. scribed to be posterior (midline) and posterolateral (interlaminar) both of which involved dural penetration $(15,16)$. The lateral (extralaminar) approach to the disc was initially described by McCulloch (17) and the oblique approach by Aprill(28) using fluoroscopic guidance. Proponents of discography feel a painful symptomatic IDD can be identified reliably with proper discographic technique $(9,18-20)$.

Fluoroscopy is used in many procedures, including swallowing studies, urologic evaluations, peripheral joint injections, and perhaps most commonly, interventional spine procedures. Conventional fluoroscopy which consists of an $\mathrm{x}$-ray tube located above a fixed examining table has been widely replaced by Carm fluoroscopes with image intensification for use in spinal injection procedures. The C-arm permits the physician to rotate and angle the $\mathrm{x}$-ray tube around the patient while the patient rests on a radiolucent support table. Image intensification is achieved through the addition of an image intensifier which receives remnant $\mathrm{x}$ ray beams that have passed through the patient and converts them into light energy, thereby increasing the brightness of the displayed image and making it easier to interpret.

Studies have been performed to eval- uate the risks to orthopedic surgeons under fluoroscopy (21-23) cardiologists in cardiac catheterization (24) urologists during endourologic procedures (25) and interventional radiologists performing a variety of visceral and peripheral angiographic procedures (24). The measurement for recording exposure is the rad equivalent man (rem) which can be measured using a dosimetry badge. (Table 1). The reader is referred to other more extensive reviews of radiation quantities, units and terminology $(26,27)$.

The above studies and ours examined radiation exposure levels using dosimetry badges, which allow the extent of exposure to be recorded. The study was performed to evaluate radiation exposure per procedure to the spinal interventionalist performing lumbar discography. A MEDLINE search of the current medical literature did not reveal any such study, and our concern for the level of radiation exposure to spinal interventionalists led to this study.

\section{Methods}

Thirty seven (37) consecutive patients over a 3-month period presented to a multidisciplinary spine care practice with complaints of lower back pain were included in this evaluation. Patients were 
Table 1. Radiation Quantities and Units

\begin{tabular}{|l|l|c|c|}
\hline Quantity & Conventional Unit & SI Unit & Conversion \\
\hline Exposure & Roentgen $\mathbb{}$ & Coulomb/ kg of air (c/kg) & $1 \mathrm{C} / \mathrm{kg}=3876 \mathrm{R}$ \\
\hline & & & $1 \mathrm{R}+258 \mathrm{\mu C} / \mathrm{kg}$ \\
\hline & & & $1 \mathrm{R}=2.58 \times 10 \mathrm{C} / \mathrm{kg}$ \\
\hline & Rad(100 ergsg) & Gray(Gy) (joule $/ \mathrm{kg})$ & $1 \mathrm{~Gy}=100 \mathrm{rad}$ \\
\hline & & & $1 \mathrm{cGy}=1 \mathrm{rad}$ \\
\hline & & & $1 \mathrm{mGy}=100 \mathrm{mrad}$ \\
\hline & & Sievert (Sv) & $1 \mathrm{~Sv}=100 \mathrm{rem}$ \\
\hline & Rem & & $0.01 \mathrm{~Sv}=1 \mathrm{cSv}=1 \mathrm{rem}$ \\
\hline & & & $0.01 \mathrm{~Sv}=1 \mathrm{mSv}=100$ \\
\hline
\end{tabular}

*Adapted from Wycoff (26)

referred by orthopedic spine surgeons for diagnostic lumbar discography to try and determine if discogenic pain was present.

Inclusion criteria thus consisted of consecutive patients who presented to the spine care center with low back pain who were referred by orthopedic spine surgeons for diagnostic lumbar discography. No patient was excluded. A total of 106 discograms (levels) were performed in the 37 consecutive patients.

A similar technique was used in all lumbar discograms. Procedures were performed by four physicians with similar training in discography. The technique was described by Aprill (28). Patients were placed in an oblique position with the most painful side down on a radiology table. Their backs were prepared by using an iodine-based antiseptic solution (Povidone iodine prep solution, Baxter, Deerfield, IL), and alcohol solutions (Swan 70\% isopropyl alcohol, Cumberland-Awan, TN). Light sedation using 1$2 \mathrm{mg}$ Midazolam was given incrementally to promote tolerance of the procedure without impairing the patient's ability to participate. Using a fluoroscope (OEC $\AA$ Compact 7600 Salt Lake City, UT), 22 gauge 6 or 8 inch spinal needles (Quincke type point, luer lock, Spinocan, Becton Dickinson $\AA$, Rutherford, NJ) were guided under intermittent fluoroscopic guidance in oblique view just anterior to the superior articular process and into the intervertebral disc. Both an anteroposterior (AP) and lateral fluoroscopic view was obtained to confirm that the needle was placed in the center of the intervertebral disc. Aspirations were routinely performed. If no blood or cerebrospinal fluid was aspirated, Isovue M-300 (iopamidol injection Bracco Diagnostics, Princeton, NJ) $1 \mathrm{ml}-2 \mathrm{ml}$ was instilled to confirm the location in the disc, exclude epidural flow of the injectate, and to rule out intravascular, intrathecal and/or soft tissue infiltration mixed with the Isovue was $10 \mathrm{mg}$ Ancef per ml of Isovue. Similar technique was utilized at all intervertebral disc levels except the L5/S1 intervertebral disc. This level required a double needle technique. Initially utilizing an oblique fluoroscopic view the superior articular process of the S1 facet was identified. An 18-gauge 3.5 inch introducer needle was inserted until contact with the bone of the superior articular process(SAP) was made. Then a 22 gauge 6 or 8 inch spinal needle was placed thru the introducer just anterior to the SAP and advanced into the intervertebral disc. The needle curvature and bevel allowed the interventionalist to properly advance the needle into the disc at all levels. Nucleograms were interpreted based upon the classification scale described by Adams et al(29). The patients were asked to characterize their pain regarding the quality, intensity, distribution and concordance during the procedure. Plain radiographs were taken in the AP and lateral views of all discograms to document both the contrast flow pattern and needle placement. All patients were monitored by pulse oximetry, blood pressure and EKG monitoring prior to, during, and after the procedure. Patients were transferred to the recovery unit for $40 \mathrm{~min}$ utes. All patients were seen by the physician who performed the injection and by a registered nurse prior to discharge.

All discograms were performed at an ambulatory care center using c-arm fluoroscopic guidance. The C-arm fluoroscope (OEC Compact 7600, Salt Lake City, UT) used was operated in snap shot (pulsed imaging) mode. X-ray voltages are measured in kilovolts peak $(\mathrm{kVp})$. In the pulsed mode a high energy penetrating $x$-ray beam was created with the image intensifier delivering a high $\mathrm{kVp}$ (The peak value of high voltage generator output in the interval after a 20 millisecond delay period to the end of the exposure) based on the patients weight and a fixed current of $8 \mathrm{~mA}$ (milliamps) using the snapshot mode. In this mode beam collimation constricted the $\mathrm{x}$-ray beam to the lumbar spine. These procedures were performed by one of four spinal interventionalists with extensive experience in lumbar discography.

The measurement for recording radiation exposure is the millirad equivalent man(mREM). (Table 1). Radiation exposure was monitored by using a Landauer (Glenwood, IL) dosimetry badge with a lower limit of detectablility of 1mREM. A radiographic technologist (RT) allocated four (4) badges to the physicians prior to the procedures. The badges were clearly marked as 1 . Outside, 2 . Inside, 3. Ring and 4. Glasses. The "Outside" badge was placed outside the lead apron worn by all the interventionalists, which was of $0.55 \mathrm{~mm}$ thickness (ProTech, Palm Beach Gardens, FL). The "Inside" badge was placed at the shirt pocket level under the apron. The "Ring badge was placed on the ring finger of the dominant hand. The "Glasses" badge was placed on the frame of lead glasses (ProTech ${ }^{\circledR}$ leaded eyewear, Palm Beach Gardens, FL) that the interventionalist wore during the procedure. A control badge was placed on a shelf on the wall 167.5 centimeters away, horizontally and 140 centimeters vertically, from the fluoroscopic table in the treatment room. A second control badge was also placed over 15 meters outside the fluoroscopy room to evaluate for any ambient radiation. When badges were not in use they were all placed together with the second control badge, outside the treatment room.

The RT's entered into a daily log the patients name, date of procedure, medical record number, procedure level, total fluoroscopy time, voltage in $\mathrm{kVp}$ (kilovolts), amperage in milliamps ( $\mathrm{mA})$, physician performing procedure and weight of the patient. Physicians entered into the log the patients' diagnosis of low back pain based upon history and physical examination.

Following completion of all 106 discograms (levels) the dosimetry badges were sent to Landauer for interpretation. The radiation dosimetry report from Landauer included the dose equivalent mREM (the unit of occupational ra- 
diation exposure and is used to monitor personnel exposure devices such as film badges) for the period in which the injections were performed. Separate readings were obtained for all badges for deep dose, eye and shallow dose equivalents in mREM. Deep dose equivalent applies to external whole-body exposure and is the dose equivalent at a tissue depth of 1 centimeter $(\mathrm{cm})$. Eye dose equivalent applies to the external exposure of the lens of the eye and is taken as the dose equivalent at a tissue depth of $0.3 \mathrm{~cm}$. Shallow dose equivalent applies to the external exposure of the skin or an extremity, and is taken as the dose equivalent at a tissue depth of $0.007 \mathrm{~cm}$ averaged over an area of one square centimeter. The total amount of mREM for each badge was obtained and the amount of mREM per second of fluoroscopy use was calculated. All reports were reviewed and complied by the radiographic technologist.

Statistical analysis was performed using a paired difference t-test. Our objective was to determine if there was a statistically significant greater exposure time at a certain intervertebral level versus another. We also wanted to determine if there was a statistically significant greater exposure at the different recording sites taken from the interventionalists. A significant p-value was less than 0.05 .

\section{Results}

A total of 106 discograms on $37 \mathrm{pa}$ tients (19 female and 18 male) were performed. There were a total of 106 procedures (levels studied) in 37 patients. The levels studied included 35 at L5-S1, 33 at $\mathrm{L} 4-5,33$ at L3-4, 4 at L2-3, and 1 at L12 . The total time in seconds at each level was tabulated and the mean number of seconds per level calculated (Table 2). The total mean fluoroscopy time per procedure was 57.24 seconds. The total flu-

Table 2. Total fluoroscopy time (seconds) per level, number of procedures at each level and mean number of seconds per level

\begin{tabular}{|c|c|c|c|}
\hline $\begin{array}{c}\text { Discogram } \\
\text { Level }\end{array}$ & $\begin{array}{c}\text { Total number of } \\
\text { procedures at } \\
\text { each level }\end{array}$ & $\begin{array}{c}\text { Total Fluoroscopy } \\
\text { Time (seconds) }\end{array}$ & $\begin{array}{c}\text { Fluoroscopy Time per level } \\
\text { (seconds) } \\
\text { (95\% Confidence Intervals) }\end{array}$ \\
\hline L5-S1 & 35 & 2446 & $69.83(57.46-82.20)$ \\
\hline L4-5 & 33 & 1878 & $55.15(45.07-65.24)$ \\
\hline L3-4 & 33 & 1563 & $47.36 \quad(37.39-57.73)$ \\
\hline L2-3 & 4 & 171 & 42.75 \\
\hline L1-2 & 1 & 66 & 66.00 \\
\hline
\end{tabular}

oroscopy time at all levels was $6124 \mathrm{sec}-$ onds in the patients. The range of fluoroscopy time per discogram level was 20 134 seconds. The mean weight of the patients studied was 175.3 pounds (lbs). The weight range of males was 150 to 225 lbs. and the weight range of females was 100 to 265 lbs. The mean male weight was 192.0 lbs. and the mean female weight was 159.4 lbs. The mean age of patients was 43.7 years. (Table 3 )

The mean $\mathrm{kVp}$ received by female patients was 97 at $8 \mathrm{~mA}$ and 100 at $8 \mathrm{~mA}$ in male patients ( Table 3 ).

The exposure to the spinal interventionalist was calculated in mREM for all 106 discograms from dosimetry badges. The exposure "outside" apron was 251 mREM (deep dose equivalent), "inside" apron was 19 mREM, "glasses" exposure was 159 mREM (eye dose equivalent) and "ring" exposure was measured to be 390 mREM (shallow dose equivalent). The control badge which was placed inside the room 167.5 centimeters away horizontally and 140 centimeters vertically from the fluoroscopy table recorded an exposure of 78 mREM deep dose equivalent. The exposure recorded from outside room badge was 0mREM deep dose equivalent (Table 4).

We were able to calculate the expo- sure per discogram at the ring, glasses, outside and inside apron recording sites. (Table 4) From this calculation one can roughly estimate the exposure to a certain site depending on the duration of a procedure.

In total 106 lumbar discograms were performed, 35 were at the L5-S1 level, 33 at the L4-5 level, 33 at L3-4 level, 4 at the L2-3 level, and 1 at the L1-2 level. Due to the small sample sizes in the last two categories, they were excluded from analysis. For the remaining samples, $\mathrm{t}$-tests were performed to see if a statistically significant difference existed in exposure time between the levels. The average exposure time for the L3-4 level was 47.36 seconds (95\% CI: $37.39-57.33$ ), for the L4-5 level, 55.15 seconds (95\% CI: 45.07-65.24), and for the L5-S1 level 69.83 seconds (95\% CI: 57.46 to 82.20 ). A statistically significant difference in exposure time was found between the L3-4 and L5-S1 levels (p-value $=0.0076)$, as well as the L4-5 and L5-S1 levels (0.0094).

Next comparisons were made to see if a difference existed in the amount of radiation exposure between the outside of the apron and the inside of the apron. Also we evaluated if the amount of radiation exposure differed between the outside of the apron, the glasses, and the ring.
Table 3. Patient Demographics and Fluoroscopy Time

\begin{tabular}{|l|l|}
\hline Total number of patients & 37 \\
\hline Total number of discograms (levels) & 106 \\
\hline Mean Age (years) (Range) & $43.7 \quad(32-70)$ \\
\hline Mean Weight (pounds) males (Range) & $192 \quad(155-265)$ \\
Mean Weight (pounds) females (Range) & $159 \quad(100-231)$ \\
Mean Weight (pounds) all patients & $175 \quad(100-265)$ \\
\hline Total Fluoroscopy Time (seconds) & 6124 \\
all discograms & $20-134$ \\
\hline Range of Fluoroscopy Time (sec) & \\
\hline
\end{tabular}

Table 4. Total cumulative mREM recorded by Dosimetry badges

\begin{tabular}{|l|c|cc|}
\hline Dosimetry badge site & $\begin{array}{c}\text { Cumulative } \\
\text { mREM } \\
\text { (SD) }\end{array}$ & $\begin{array}{c}\text { mREM per } \\
\text { Procedure } \\
\text { (SD) }\end{array}$ \\
\hline Interventionalist "ring" & $390 \quad( \pm 9.750)$ & $3.66( \pm 0.915)$ \\
\hline Interventionalist "outside apron" & $251 \quad( \pm 6.275)$ & $2.35 \quad( \pm 0.635)$ \\
\hline Interventionalist "glasses" & $159( \pm 3.975)$ & $1.49 \quad( \pm 0.373)$ \\
\hline Interventionalist "inside apron" & $19 \quad( \pm 0.475)$ & $0.18 \quad( \pm 0.004)$ \\
\hline Inside Room control badge & $78( \pm 1.95)$ & $0.74 \quad( \pm 0.185)$ \\
\hline Outside Room control badge & \multicolumn{2}{|c|}{0} & \multicolumn{2}{|c|}{0.00} \\
\hline
\end{tabular}


The total amount of radiation exposure on each badge was obtained after all 106 procedures were performed. The total exposure was divided by the total time taken by all the procedures (6124 seconds). This gave us the average amount of radiation exposure per second. This number was multiplied by the number of seconds for each procedure. This result was the total amount of radiation exposure per procedure. The average exposure to the outside of the apron was 2.35 mREM (95\% CI: $2.09-2.61)$ and to the inside of the apron 0.18 mREM (95\% CI: 0.157 - 0.197). A paired difference t-test was performed comparing the exposure to the outside of the apron versus the inside. A p-value of $<.0001$ was obtained. From this we concluded that the outside of the apron received significantly more radiation exposure than the inside. We then compared exposure to the ring, glasses, and outside of the apron. Once again a highly significant p-value was obtained (<.0001) with the ring having the greatest exposure to radiation with an average of 3.66 mREM (95\% CI: $3.26-4.07)$. The average exposure to the glasses was 1.49 mREM (95\% CI: 1.32 - 1.66).

\section{DISCUSSION}

The initial interest in the intervertebral disc acting as a pain generator was suggested by Hirsch(30). Early work performed by Lindblom showed radial annular fissures(15). In 1952 Pierre Erlacher (31) was able to correlate the nucleogram to nuclear anatomy on cadaver discs. Adams et al(29) described five types of disc degeneration identified on lumbar discograms. CT post-discography has been classified as well to aide in interpretation of results $(10,32)$. The procedure had been rejected as a diagnostic test following Holt's (33) study, which was later shown to be flawed $(34,35)$.

The complications of diagnostic lumbar discography have been well de-

Table 5. General Radiation Exposure Guidelines

\begin{tabular}{|l|l|}
\hline Type of Exposure & Annual limit \\
\hline $\begin{array}{l}\text { Whole body (head \& trunk). } \\
\text { Active blood forming }\end{array}$ & 5 rem/year \\
\hline Lens of eye & $15 \mathrm{rem} /$ year \\
\hline Extremities & $50 \mathrm{rem} /$ year \\
\hline Skin & $50 \mathrm{rem} /$ year \\
\hline \multicolumn{2}{|c|}{ Addapted from Ref. 40} \\
\hline
\end{tabular}

scribed(6,36-39). The procedure requires fluoroscopy and the radiation risk to the interventionalist has not been studied specifically with regard to this procedure.

Radiation risks to the spinal interventionalist and assisting personnel is evaluated using the maximum safe allowable exposure limits which have been established by the National Council on Radiation Protection and Measuring as a maximum permissible dose (MPD)(40). The recommendations for occupational radiation exposure can be seen in Table 5. The current estimation of risk from radiographic exposure to a specific body part is based on the biologic effects of whole-body exposure converted by weight factors specific for individual organs and tissues. This concept was adopted by the International commission on Radiological Protections in 1977 and was modified in 1991(41). Termed the effective dose equivalent, the calculation has been adopted by authoritative bodies that determine radiation risk and recommend protective measures (41).

When evaluating our data it can be seen the radiation exposure appears to be well within these regulations. If we extrapolate our data to 1000 lumbar discograms (10 times the amount studied) which could be performed annually per clinician at our center then a total radiation exposure of 3.66REM "Ring" badge, 1.49REM "Glasses" badge and 2.35REM "Outside apron" badge all would fall within general limits as per Table 5. However, depending on the volume of procedures in the spinal interventionalists' clinic, the exposure will increase accordingly and must be followed closely. The absolute exposure to the spinal interventionalist must be calculated on an individual basis and must take into account that the radiation exposure will be cumulative over the lifetime.

The typical patient who undergoes discography has a 3-level (L3-4, L4-5, L5S1) procedure performed. Extrapolating the average amount of radiation exposure to the spinal interventionalist for each level for each radiation badge and then adding each result per level can give a close estimation of radiation exposure during the real-life scenario of a 3-level discography procedure. We found that the spinal interventionalist was exposed to 7.08 mREM on the outside badge, 0.519 mREM on the inside badge, 11.05 mREM on the ring badge, and $4.43 \mathrm{mREM}$ on the glasses badge per patient for a 3-level discography procedure.

Through statistical analysis we observed the lead apron did significantly reduce the amount of cumulative radiation exposure when comparing the outside apron to inside apron dosimetry badge reading.

Statistically we found a significantly higher fluoroscopy time (seconds) at the L5/S1 level versus the L4/5 or L3/4 levels. Comparison was not done to the $\mathrm{L} 2 / 3$ or L1/2 levels, as the number of procedures at these levels was disproportionately few. This correlates well with the technical difficulty in performing discography at the L5-S1 level.

Statistical analysis also revealed significantly more radiation exposure per procedure and cumulatively at the ring, outside apron and glasses recording sites to the inside room control.

Limitations of this study are several. The study assumes the technique by which fluoroscopy is utilized is similar in all physicians. In reality many different physicians perform discography and may use a different technique, which could alter the radiation exposure. The mode in which the fluoroscope is used is another variable to consider. If live fluoroscopy is utilized throughout the procedure, radiation exposure may vary as well. Further study should be done in a prospective multicenter study to see if the exposure is higher with live versus pulsed fluoroscopic guidance. It should also include patient exposure.

The study proved the effectiveness of leaded aprons in reducing exposure. Further study should be done to assess the effectiveness of leaded gloves and glasses.

The study could also be improved upon, if the dosimetry badges are interpreted after each and every discogram(level). Obviously the cost of this is a factor, which would have to be overcome for a more accurate means of recording radiation exposure in discography.

The use of leaded aprons, glasses, thyroid shields and lead barriers seem most appropriate to minimize the spinal interventionalists exposure. This has been found by other authors(42). It should be noted the long term effects of low dose radiation are uncertain (43). The exposure in our study was greater to the hands, than eyes of our interventionalists, which may argue for even the use of leaded gloves in 
addition to leaded glasses. Also extended tubing for administering radiographic contrast may be of benefit.

Radiation exposure results from the primary beam and scatter radiation reflected off the floor and the patient. The cardinal principles of radiation protection are: (1) maximize the distance from the radiation source; (2) use shielding materials; and (3) minimize exposure time. Technical factors using the fluoroscope may serve to reduce both occupational and patient exposure. Using pulsed imaging during fluoroscopy has been shown to reduce overall exposure by $20-75 \%(44,45)$. The usage of collimation also reduces unnecessary radiation exposure (44).

A radiation safety program may serve to minimize exposure to ionizing radiation while promoting safe and effective use of radiation sources in diagnosis, therapy and research. One goal of such a program is to keep the risks to radiation workers to levels that are comparable to those of other safe occupations. The pervading philosophy is that of "as low as reasonably achievable” (ALARA) (46).

Adhering to simple rules of radiation safety can minimize the cumulative exposure to the spinal interventionalist. These include increasing distance between the interventionalist and the source of radiation, decreasing the overall time of exposure, shielding susceptible areas with leaded aprons, thyroid shields, leaded glasses and leaded gloves as well as being proficient in guiding needles under fluoroscope.

This study revealed a level of radiation exposure to be below the maximal permissible dose. Other studies (47-49) have also shown the radiation exposure to be below the maximal permissible dose. However, the total number of procedures performed by an interventionalist must be accounted for. One must also keep aware radiation exposure is cumulative.

\section{ConCLUSION}

Our study demonstrates that the radiation exposure to the spinal interventionalist performing lumbar discography is within safety guidelines.
Author Affiliation

Kenneth P. Botwin, MD

Florida Spine Institute

2250 Drew Street

Clearwater, FL 33765

E-mail: contactus@floridaspineinst itute.com

\section{Glenn S. Fuoco, DO}

PMR Fellow

Florida Spine Institute

2250 Drew Street

Clearwater, FL 33765

Francisco M. Torres, MD

Florida Spine Institute

2250 Drew Street

Clearwater, FL 33765

Robert D. Gruber, DO

Medical Director

Florida Spine Institute

2250 Drew Street

Clearwater, FL 33765

\section{Constantine C. Bouchlas, MD}

Florida Spine Institute

2250 Drew Street

Clearwater, FL 33765

\section{Ramon Castellanos, MD}

PMR Fellow

Florida Spine Institute

2250 Drew Street

Clearwater, FL 33765

\section{Sanjiv Rao, BA}

University of South Florida

Department of Mathematics

Tampa, FL

\section{REFERENCES}

1. Schwarzer A, Aprill C, Derby R. The relative contributions of the disc and zygapophyseal joint in chronic low back pain. Spine 1994;19:801- 806.

2. Kuslich SD, Ulstrom CL, Michael CJ. The tissue origin of low back pain and sciatica: a report of pain response to tissue stimulation during operations on the lumbar spine using local anesthesia. Orthop Clin North Am 1991;22:181-187.

3. Coppes M, Marani E, Thomeer R. Innervation of "painful" lumbar discs. Spine 1997;22:2342-2350.

4. Bogduk N. Clinical Anatomy of the Lumbar Spine and Sacrum. 3rd ed. Churchill Livingstone, Edinburgh 1997, pp 202-212.

5. Bogduk N. The lumbar disc and low back pain. Neurosurg Clin North Am 1991;2:791 806.

6. Merskey H, Bogduk N (eds). In Classifica- tion of chronic Pain $2^{\text {nd }}$ ed. Descriptions of Chronic pain Syndromes and Definitions of Pain Terms, IASP Press, Seattle, WA, 1994.

7. Fortin JD, Sehgal N, Nieves RA. Lumbar and thoracic discography with $\mathrm{CT}$ and MRI correlations in Lennard T A( ed). Pain Procedures in Clinical Practice. Hanley and Belfus, Philadelphia, 2000, pp 241-265.

8. Windsor RE, Falco FJE, Dreyer SJ et al. Lumbar Discography. Physical Medicine and Rehabilitation Clinics of North America 1995;6:743- 766.

9. North American Spine Society. Position statement on discography. The Executive Committee of the North American Spine Society. Spine 1988;13:1343.

10. Bernard TN. Lumbar discography followed by computed tomography. Refining the diagnosis of low-back pain. Spine 1990;15: 690-707.

11. Derby R, Eek B, Chen, O'Neill et al. Intradiscal electrothermal annuloplasty (IDET): A novel approach for treating chronic discogenic back pain. Neuromodulation 2000;3:2:82-88.

12. Saal JS, Saal JA. Management of chronic discogenic low back pain with a thermal intradiscal catheter. A preliminary report. Spine 2000;25:382-388.

13. Saal JA, Saal JS. Intradiscal electrothermal treatment for chronic discogenic low back pain. A Prospective outcome study with minimum one-year follow up. Spine 2000;25:2622-2627.

14. Karasek M, Bogduk N. Twelve-month follow-up of a controlled trial of intradiscal thermal annuloplasty for back pain due to internal disc disruption. Spine 2000;25: 2601-2607.

15. Lindblom K. Diagnostic puncture of the intervertebral discs in sciatica. Acta Orthop Scand 1948;17:231-239.

16. Keck C. Discography. Technique and interpretation. Arch Surg 1960;80:580-585.

17. McCulloch JA, Waddell G. Lateral lumbar discography. BrJ Radio1978;|51:498 502.

18. Simmons EH, Segil CM. An evaluation of discography in the localization of symptomatic levels in discogenic disease of the spine. Clin Orthop Rel Res 1975;108: 5769.

19. Horton WC, Daftatir TK. Which disc as visualized by magnetic resonance imaging is actual a source of pain? A correlation between magnetic resonance imaging and discography. Spine 1992;17:S164-171.

20. Bogduk N, Modic MT. Controversy. Lumbar discography. Spine 1996;21:402-404.

21. Giachino, AA, Cheny M. Irradiation of the surgeon during pinning of femoral fractures. J Bone Joint Surg Br 1980; 62: 227229.

22. Miller ME, Davis ML, MacClean CR et al. Radiation exposure and associated risks to operating room personnel during use of fluoroscopic guidance for selected orthopedic surgical procedures: / Bone Joint 
Surg Br 1983;65:1-4.

23. O'Rourke PJ, Crevard S, Harrington P et al. Risks of radiation exposure to orthopedic surgeons. J R Coll Surg Edinb 1996;41:4043.

24. Miller SW, Castrovovo FP. Radiation exposure and protection in cardiac catheterization laboratoris: AJ Cardiology 1985; 55: 171-176.

25. Giblin JG, Rubenstein J, Taylor A et al. Radiation risk to the urologist during endourologic procedures, and a new shield that reduces exposure. Urology 1996;48: 624627.

26. Wycoff HO. The international system of units. Radiology 1978; 128:833-835.

27. Gruber RD, Botwin KB, Shah CP. Radiation safety for the physician in Lennard $T A$ ( Ed). Pain Procedures in Clinical Practice, $2^{\text {nd }} \mathrm{Ed}$, Hanley and Belfus, Philadelphia 2000; pp 25-32.

28. Aprill CN: Diagnostic disc injection. In Frymoyer JW (ed): The Adult Spine: Principles and Practice. Lippincott -Raven Press, New York, 1975, pp23 -562.

29. Adams M, Polan P, Hutton W: The stage of disc degenerations as revealed by discograms. J Bone Joint Surg Br 1986;68:3641.

30. Hirsch C. An attempt to diagnose the level of a disc lesion clinically by disc puncture. Acta Orthop Scand 1948;18:131-140.

31. Erlacher PR. Nucleography. J Bone Joint Surg Br 1952;34:204-210.

32. Sachs BL Vanharanta H, Spivey MA. Dallas discogram description. A new classification of $\mathrm{CT} /$ discography in low back dis- orders. Spine 1987;12:287-294.

33. Holt EP Jr. The question of lumbar discog raphy. J Bone Joint Surg Am 1968;50A:720726.

34. Simmons JW, Aprill CN, Dwyer AP A reassessment of Holt's data on "the question of lumbar discography". Clin Ortho Res 1988;237:120-127.

35. Walsh T, Weinstein J, Spratt K. Lumbar discography in normal subjects. Controlled prospective study. J Bone Joint Surg Am 1990;72A:1081- 1088.

36. Guyer RD, Collier R, Stith WJ. Discitis after iscography. Spine 1988;13:1352-1354.

37. Osti OL, Fraser RD, Vernon-Roberts B. Discitis after discography. The role of prophylactic antibiotics. J Bone Joint Surg Br 1990;72:271-274

38. Junila J, Niinimaki T, Tervonen O. Epidural abcess after lumbar discography. A case report. Spine 1997;22:2191-2193.

39. Windsor RE, Pinzon EG, Gore HC. Complications of common selective spinal injections: prevention and management. $\mathrm{Am}$ J Orthop 2000;10:759-770

40. National Council on Radiation Protection and Measurements (NCRP): lonizing Radiation Exposures of the Population of the United States. Report No. 116, Washington, DC, NCRP, 1993.

41. International Commission on Radiological Protection: Recommendation of the International Commission on Radiation Protection 26. Ann Int. Commission Radiat Prot 1977;1:1-53.

42. Marx VM, Niklason L, Mauge EA. Occupational radiation exposure to the interven- tional radiologist: a prospective study: JVIR 1993;3:597-606

43. Adelstein SJ. Uncertainty and relative risks of radiation exposure. JAMA 1987;258: 655-657

44. denBoer A, deFeyter PJ, Humuel WA et al. Reduction of radiation exposure while maintaining high-quality fluoroscopic images during intertectional cardiology using novel X-ray tube technology with extra beam filtering. Circulation 1994;89:2710-4

45. Hernandez RJ, Goodsitt MM. Reduction of radiation dose in pediatric patients using pulsed fluoroscopy. Am J Roentgenol 1996;167:1247-53

46. National Council on Radiation Protection and Measurements. Implementation of the principle of as low as reasonably achievable (ALARA) for medical and dental personnel. Bethesda(MD): NCRP; 1990. NCRP Report No. 107

47. Botwin KP, Thomas S, Gruber RD et al. Radiation exposure of the spinal interventionalist performing fluoroscopically guided lumbar transforaminal epidura steroid injections. Arch Phy Med Rehabil 2002;83: 697-701

48. Botwin KP, Freeman ED, Gruber RD et al. Radiation exposure to a physician performing fluoroscopically guided caudal epidural steroid injections. Pain Physician 2001;4:343-348

49. Manchikanti LM, Cash KA, Moss TL et al. Radiation exposure to the physician in interventional pain management. Pain Physician 2002;5:385-393 